\title{
EVALUASI PERTUMBUHAN PASAR REITS DI SINGAPURA, MALAYSIA, THAILAND, \& HONGKONG SEBAGAI PEMBANDING PASAR DIRE DI INDONESIA
}

\author{
Cita Vaga \\ Program Studi Magister Manajemen Universitas Tarumanagara \\ citavaga@gmail.com
}

\begin{abstract}
This research aims to understand the history of REITs market in Singapore (SREITs), Malaysia (M-REITs), Thailand (Thai-REITs), and Hongkong (HK-REITs), along with the curent regulation, with the intention to figure out the differences between markets thus lessons can be learned to boost DIRE's market in Indonesia. Purpose of this research is to understand the background of REITs growth in Singapore, Malaysia, Thailand, and Hongkong, along with understanding the regulations and differences. By understanding those, one can help to understand how the regulation can help DIRE and invigorate DIRE's market. Qualitative descriptive model research is done to obtain information as mention above.

The conclusion of this research is DIRE have experience the same occurence as other successful REITs market in the region. Regulators have amend the regulations to invigorate the market. While other comparisons have succesfully develop REITs market, DIRE is still stagnan in zero growth condition. Only after comparing the regulations, it is revealed that DIRE's gearing ratio and income taxes might hinders its growth to be as fast as other comparison. Regulators need to improve these conditions to increase interest towards DIRE.
\end{abstract}

Keywords: REITs, DIRE, Qualitative Descriptive, Regulations, Gearing Ratio, and Tax

\section{PENDAHULUAN}

Pertumbuhan sektor properti di Indonesia sangat menjanjikan karena pertumbuhannya yang stabil namun terus meningkat, baik dari dilihat dari kontribusnya terhadap PDB maupun dari realisasi penanaman modal asing, yang menunjukan bahwa potensi properti masih belum selesai digali. Berdasarkan pengamat properti seperti Jones Lang LaSalle maupun laporan Global Property Guide tahun 2016, Indonesia adalah lokasi investasi properti dengan yang pengembalian sewa tahunannya lebih tinggi $(8,61 \%)$ bila dibandingkan Thailand (5.13\%), Malaysia (4,53\%), Hongkong (2,75\%), dan Singapura $(2,54 \%)$.

Model investasi pada sektor properti juga mengalami pengembangan, tidak hanya dalam format jual beli banguna atau tanah, tetapi juga antara lain melalui jual beli saham perusahaan properti, yang saat ini harga sahamnya relatif stabil dengan pertumbuhan 5\% pada tahun 2016. Selain jual beli saham properti, model investasi properti lain, yaitu Dana Investasi Real Estat (DIRE) juga diperkenalkan pada pasar indonesia di tahun 2007. DIRE adalah model investasi yang mengadopsi model REITs yang pertama kali diperkenalkan di Amerika Serikat pada tahun 1960an sebagai sarana investasi properti yang terjangkau bagi masyarakat umum.

Pada model REIT, institusi (pengelola) akan menjual kepemilikan atas unit yang mewakili bagian dari properti yang diakuisisi oleh institusi. Dibandingkan dengan membeli unit properti yang harganya terus meningkat, unit REIT dijual pada harga yang lebih terjangkau. Jepang pada 2001 adalah negara pertama yang memperkenalkan model REIT dan diikuti oleh Singapura pada 2002. Hingga akhir 2016, Hongkong, Malaysia, Thailand, dan Korea Selatan telah memperkenalkan model REITs di negaranya walau tidak semuanya mengalami kesuksesan signifikan. Selain Jepang, pasar REITs di Singapura, Hongkong, 
Malaysia, dan Thailand menunjukan pertumbuhan yang menjanjikan, antara lain melalui aktifnya institusi REITs baru terus bertumbuh. Hal yang berbeda dialami oleh DIRE dimana semenjak pertama kali diluncurkan, hanya satu institusi yang terdaftar yaitu DIRE Ciptadana Properti Ritel Indonesia.

Hal tersebut menunjukan bahwa DIRE praktis tidak berkembang di Indonesia, maka penelitian ini bertujuan untuk memahami pasar dan regulasi REITs pada negara lain yang dapat dijadikan acuan untuk mengembangkan pasar DIRE di Indonesia.

\section{TINJAUAN PUSTAKA \& METODOLOGI}

REIT (Real Estate Investment Trust) seperti telah dijelaskan pada latar belakang pada esensinya merupakan sebuah badan pendanaan yang diciptakan secara eksklusif untuk memiliki asset properti, asset terkait pendanaan properti (KPR), atau kedua jenis asset tersebut (Su, Erickson, \& Ko, 2003). Sebelum diciptakan model REIT, investor hanya dapat memiliki properti bila membeli secara langsung, namun dengan adanya REIT, maka investor dimungkinkan untuk melakukan jual beli properti di pasar saham karena properti secara transaksi telah diubah bentuknya menjadi sebuah perusahaan atau perserikatan.

Menurut Su, Erickson, \& Ko (2003), REIT dapat dilihat sebagai sebuah gabungan aset properti yang diperjualbelikan di pasar saham, sehingga investor REIT harus dapat memahami pasar saham maupun pasar properti agar memiliki pemahaman investasi yang baik. Namun demikian, saham REIT tidak serta merta sama dengan saham pada umumnya, dimana harga saham umum dapat berubah setiap waktu, sedangkan harga properti tidak berubah demikian cepatnya. Walaupun harga saham REIT seharusnya setara dengan nilai properti yang diwakili, harga saham REIT tidaklah selalu sama.

Menurut BNP Paribas dalam rilisnya, REIT menyediakan metode yang relatif cair bagi investor untuk memiliki aset properti tanpa harus langsung membeli properti tersebut. REIT adalah saham dari perusahaan atau persekutuan yang terdaftar di bursa atau tidak, yanng mengelola portofolio dari properti yang menghasilkan pemasukan rutin, seperti pusat perbelanjaan, perkantoran, maupun apartemen.

REIT dapat memberikan investasi yang stabil dan terprediksi dari memiliki dan menyewakan properti, namum tetap memiliki benefit sebagai bentuk investasi yang mudah diperjual belikan. REIT dapat memberikan stabilitas dalam portfolio investasi (Block, 2012). REIT dapat menghasilkan arus kas yang lebih besar saat nilai aset meningkat dan mendapatkan penambahan aset baru.

Sesuai dengan judul penelitian ini, yaitu “Analisis Kunci Keberhasilan DIRE Berdasarkan Keberhasilan REITS di Singapura, Malaysia, Thailand, dan Hongkong Sebagai Pembanding Pasar DIRE di Indonesia", penelitian serupa telah dilakukan oleh Ooi, Newell, \& Sing (2006) dalam "The Growth of REITs Market in Asia" dengan mengamati latar belakang dan sejarah pertumbuhan REITS di Asia (Jepang, Korea Selatan, Singapura, Taiwan, Hong Kong, dan Malaysia) dari sisi ekonomi makro, pasar keuangan dan pasar properti. peneliti mengamati faktor - faktor pendorong pertumbuhan REITS dari sisi permintaan, inisiatif pemerintah, serta hambatan yang timbul dalam perjalanannya. Hasil penelitian menunjukan kecenderungan regulasi dari pemerintah mendorong keberhasilan REITS pada suatu negara. Penelitian juga menunjukan alasan lain REITS berhasil adalah performanya yang relatif stabil serta keamanan melalui adanya aset (properti) menarik bagi investor karena resiko relatif lebih rendah dari pasar saham.

Pada tahun 2010, Newell \& Osmadi dalam tulisannya yang berjudul "Assessing the Importance of Factor Influencing the Future Development of REITS in Malaysia", menyatakan bahwa REITS Malaysia yang mulai diperkenalkan pada tahun 2005 telah mengalami perkembangan yang pesat pada tahun 2009, dengan telah tercatatnya 13 REITS. Penelitian ini menunjukan bahwa keberhasilan REITS pada Malaysia dipengaruhi oleh regulasi pemerintah melalui peringanan pajak, adanya pengelola aset profesional, serta variasi 
aset yang dianggap menguntungkan. Penyedia REITS juga dapat melihat peluang sosial budaya religi penduduk Malaysia yang didominasi penduduk Muslim, sehingga REITS yang mengadopsi konsep syariah berkembang luas serta sangat diminati. Penelitian ini turut membuktikan bahwa regulasi dari pemerintah serta kecapakan strategi pengembangan dengan melihat budaya masyarakat merupakan pendorong kemajuan REITS di Malaysia

Hong Kong sebagai salah satu pasar properti komersial paling dinamis di Asia juga telah diamati pertumbuhannya oleh Newell, Yue, Chau, \& Wong (2010) dalam "The Development \& Performance of REITS in Hong Kong". Penelitian ini menjelaskan mengenai sejarah pertumbuhan REITS di Hong Kong beserta perubahan regulasi, dimana HK-REITS memungkinkan properti yang berlokasi di luar Hong Kong untuk didaftarkan sebagai aset. Opsi ini menawarkan flexibilitas baik kepada perusahaan REITS maupun kepada investor, sehingga pasar HK-REITS mengalami pertumbuhan yang sangat pesat.

Jurnal - jurnal serta publikasi terdahulu yang dijadikan acuan menunjukan adanya faktor yang telah terbukti secara historis menjadi faktor pendorong pertumbuhan REITS , yaitu perubahan regulasi yang meringankan secara perpajakan, kebijakan pembagian hasil atau dividen yang jelas, tersedianya properti unggulan yang memiliki penghasilan besar, adalah beberapa faktor yang secara umum disebutkan dalam penelitian tersebut sebagai pendorong.

Berdasarkan tinjauan pustaka serta penelitian mengenai performa REITS, maka penulis mendapatkan beberapa hipotesis sebagai berikut :

- Regulasi pemerintah antara lain mengenai implikasi pajak serta pembagian dividen merupakan salah satu faktor pendorong kesuksesan dari REIT di sebuah negara

- Negara dengan regulasi yang lebih suportif akan memiliki performa REIT terhadap saham properti yang lebih baik

Metodologi yang digunakan dalam melakukan penelitian ini adalah dengan menggunakan metode kualitatif deskriptif, yaitu dengan memberikan penjabaran mengenai perkembangan, sejarah, dan regulasi, tanpa menggunakan metode statistic.

\section{PEMBAHASAN}

Berdasarkan lini waktu dari pertumbuhan REITs pada Singapura, Malaysia, Thailand, dan Hongkong, diketahui bahwa regulasi pertama yang diterbitkan sebagai dasar pembentukan REITs terbukti kurang efektif dalam mendorong pertumbuhan pasar REITs. Singapura membutuhkan waktu 3 tahun untuk menerbitkan perbaikan regulasi S-REITs, Malaysia menerbitkan regulasi serupa REITs pada tahun 1989 tetapi baru pada 2001 regulasi tersebut disesuaikan untuk menarik minat pasar, Thailand merevisi regulasinya setelah 8 tahun, demikian juga dengan Hongkong yang telah merevisi regulasi yang digunakan beberapa kali (tabel 1).

Regulasi yang telah direvisi pada S-REITs, M-REITs, Thai-REITs, dan HK-REITs memiliki dampak yang positif bagi pertumbuhan pasar REITs masing - masing negara. Pada tahun yang sama setelah regulasi M-REITs pertama kali di revisi (2005), tercatat bahwa terdapat 3 M-REITs baru yang mendaftar. Demikian pula dengan Singapura dan Hongkong, dimana pada tahun yang sama setelah regulasi direvisi, dua S-REITs baru resmi mendaftar pada bursa (2002) dan 3 HK-REITs baru terdaftar (2005). Namun hal demikian tidak terjadi pada DIRE, yang walaupun telah direvisi pada tahun 2016, belum ada pendaftaran baru hingga akhir 2017.

Thai-REITs memberikan kasus yang cukup berbeda dengan Malaysia dan Singapura, dimana sejak regulasi pertama diluncurkan, peminat pada model investasi ini sudah cukup tinggi. Alasan keberhasilan model PFPO (generasi pertama Thai-REITs) adalah regulasi yang diterapkan pada PFPO sudah mengadopsi regulasi REITs di Amerika Serikat. Namun regulator Thai-REITs semakin meningkatkan daya tarik Thai-REITS melalui perubahan regulasi pada tahun 2010 dan mengubah PFPO menjadi Thai-REITs. Hingga akhir 
2017, Thai-REITs adalah pasar REITs yang paling aktif diantara Singapura, Malaysia, dan Hongkong.

Indonesia bila dibandingkan dengan Malaysia, Singapura, Thailand, dan Hongkong , adalah negara yang paling akhir dalam mengadopsi model REITs. Baru pada tahun 2007 Bapepam -LK meluncurkan regulasi mengenai DIRE. Dengan sedikitnya insentif yang diberikan, hingga regulasi tersebut direvisi oleh OJK pada tahun 2016, baru terdapat 1 DIRE yang terdaftar, dan hingga belum ada DIRE baru yang terdaftar.

Selain mengamati lini waktu dari pertumbuhan S-REITs, M-REITs, Thai-REITs, HK-REITs, dan DIRE, pengamatan juga dilakukan terhadap regulasi yang diterapkan. Berikut adalah perbedaan yang dimiliki DIRE bila dibandingkan dengan negara lainnya :

- Unit DIRE, berbeda dengan REITs di Singapura, Malaysia, dan Thailand, tidak boleh dimiliki oleh warga negara asing. Namun perusahaan yang berdomisili di Indonesia tidak dibatasi atas haknya untuk memiliki unit DIRE.

- DIRE diwajibkan regulasi untuk mendistribusikan 90\% dari pendapatannya kepada pemegang unit. Berbeda dengan negara lain, dimana Singapura mendapatkan kewajiban yang sama atas dasar pengurangan pajak, tidak ada insentif khusus bagi DIRE selain atas dasar regulasi.

- Gearing ratio yang diberlakukan pada DIRE relatif kecil, mengingat besarannya hanya 45\% dari nilai aset yang akan diakuisisi. Dibandingkan dengan REITs pada Singapura, Malaysia, Thailand, dan Hongkong yang besar pinjaman didasari oleh besaran nilai bersih aset yang sudah dimiliki bukan dari nilai aset yang diakuisisi. Terbatasnya pinjaman yang dapat diajukan oleh DIRE mengakibatkan sulitnya berkembang karena batasan dana.

- Pajak penghasilan pada REITs di Singapura, Malaysia, Thailand, dan Hongkong dibebaskan pada tingkat institusi dan perseorangan saat menerima dividen. Berbeda dengan DIRE, dimana pada tingkat institusi DIRE dikenakan pajak penghasilan sebesar $10 \%$.

- Stamp Duty DIRE saat ini tingkatnya paling tinggi di tingkat regional pada 5\%.

Terlihat bahwa DIRE memiliki batasan yang lebih ketat daripada negara lain yang sudah lebih aktif pasar REITs nya. DIRE tidak boleh dimiliki warga negara asing, pendapatan wajib didistribusikan 90\% tanpa keringanan pajak, serta besaran pinjaman yang besarnya sangat terbatas. Belum lagi perpajakan yang potongannya paling besar bila dibandingkan dengan negara lainnya.

\section{KESIMPULAN}

Berdasarkan pengamatan terhadap pasar DIRE dan regulasi yang berlaku, untuk mengembangkan DIRE maka diperlukan perubahan regulasi agar lebih suportif. Terdapat beberapa aspek yang dapat direlaksasi, antara lain dengan meningkatan gearing ratio atau merubah pengali dasar, dimana saat ini pinjaman berdasar atas nilai aset yang akan diakuisisi menjadi berdasarkan nilai aset yang sudah dimiliki, seperti yang telah diberlakukan pada negara lain yang sudah lebih berhasil.

Selain itu pemberian insentif pendiadaan pajak penghasilan pada tingkat institusi, setidaknya selama 5 tahun untuk mendorong pertumbuhan pasar DIRE, regulasi ini dapat ditinjau kembali setelah 5 tahun apakah akan diteruskan atau kembali dikenakan pajak penghasilan bila pasar DIRE sudah stabil. Serta pemberian insentif terhadap besaran stamp duty hingga pasar DIRE menjadi lebih stabil dan kemudian dapat dilakukan peninjauan kembali. 
. Perbandingan Liniwaktu Pertumbuhan REITs di Singapura, Malaysia, Thailand, Hongkong, \& Indonesia

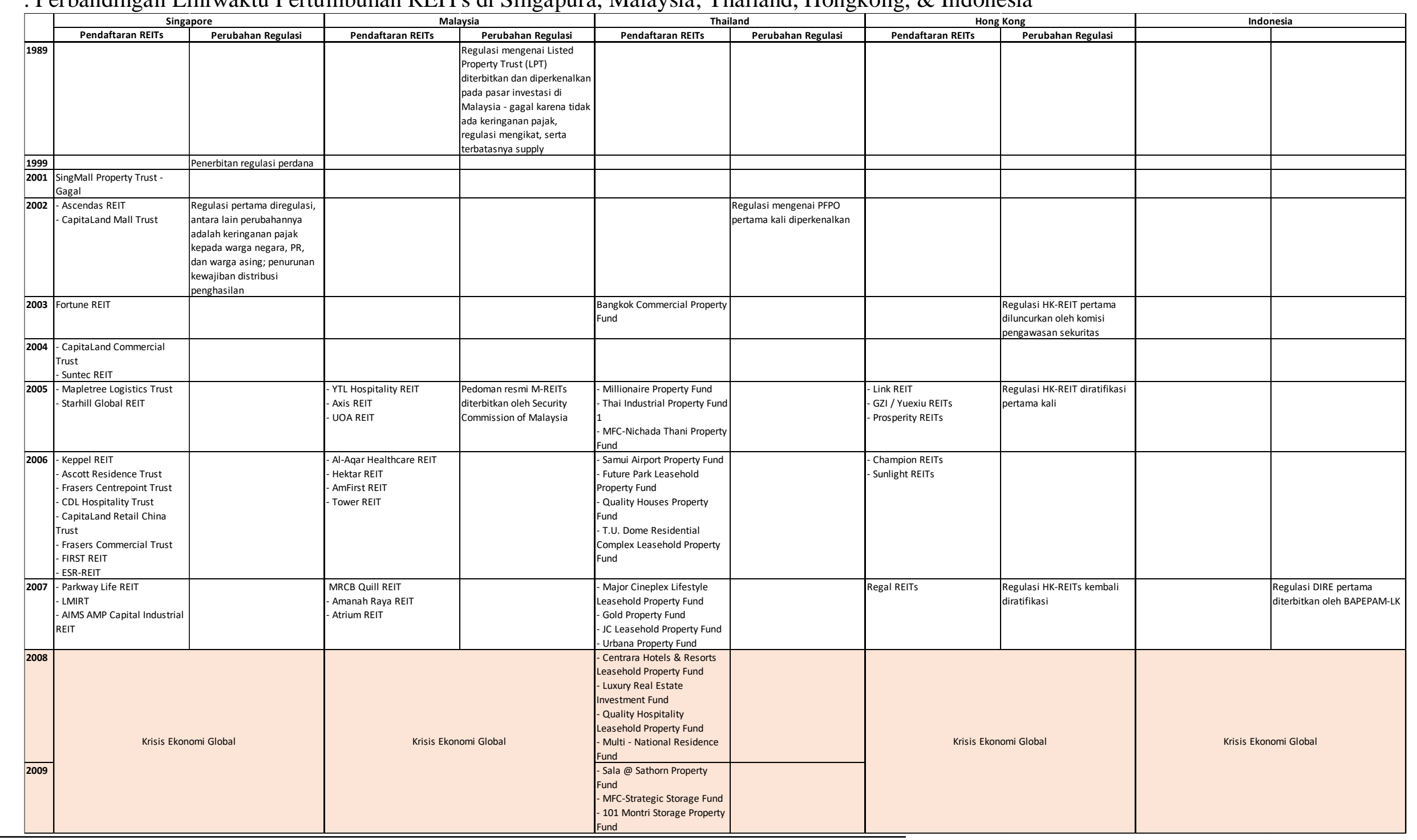




\begin{tabular}{|c|c|c|c|c|c|c|c|c|c|c|}
\hline & \multirow{2}{*}{\multicolumn{2}{|c|}{$\begin{array}{c}\text { Singapore } \\
\end{array}$}} & \multirow{2}{*}{\multicolumn{2}{|c|}{$\begin{array}{c}\text { Malaysia } \\
\end{array}$}} & \multirow{2}{*}{\multicolumn{2}{|c|}{$\begin{array}{c}\text { Thailand } \\
\text { Pa }\end{array}$}} & \multirow{2}{*}{\multicolumn{2}{|c|}{$\begin{array}{c}\text { Hong Kong } \\
\end{array}$}} & \multirow{2}{*}{\multicolumn{2}{|c|}{ Indonesia }} \\
\hline & Pendaftaran REITs & & & & & & & & & \\
\hline 2010 & $\begin{array}{l}\text { - Mapletree Industrial Trust } \\
\text { - Cache Logistics Trust } \\
\text { Sabana Shariah Compliant } \\
\text { REIT }\end{array}$ & & $\begin{array}{l}\text {-Sunway REIT } \\
\text { - Capitaland Malaysia Mall } \\
\text { REIT }\end{array}$ & & \begin{tabular}{|l} 
- Talaad Thai Leasehold \\
Property Fund \\
- Samui Bury Property fund
\end{tabular} & $\begin{array}{l}\text { Pemerintah memperbaharui } \\
\text { regulasi PFPO, mengikuti } \\
\text { konsep REIT yang lebih } \\
\text { dikenal secara global } \\
\end{array}$ & Fortune REITs & $\begin{array}{l}\text { Regulasi REIT di amandemen } \\
\text { untuk menguatkan posisi } \\
\text { investor }\end{array}$ & & \\
\hline 2011 & - Mapletree Commercial Trust & $\begin{array}{l}\text { Pemerintah Singapura } \\
\text { menerbitkan regulasi untuk } \\
\text { menangkal buble properti, } \\
\text { sehingga minat investasi } \\
\text { langsunga atas properti } \\
\text { mengalami penurunan dan } \\
\text { berpindah kepada investasi } \\
\text { atas REIT }\end{array}$ & Pavilion REIT & & $\begin{array}{l}\text { - Prime Office Leasehold } \\
\text { Property Fund } \\
\text { - Trinity } \\
\text { - Sub Sroperty Fund } \\
\text { - Suai Property Fund }\end{array}$ & & Hui Xian REIT & & & \\
\hline 2012 & \begin{tabular}{|l} 
- Far East Hospitality Trust \\
- Ascendas Hospitality Trust
\end{tabular} & & |GB REIT & & $\begin{array}{l}\text { - Tesco Lotus Retail Growth } \\
\text { Freehold \& Leasehold } \\
\text { Property Fund } \\
\text {-MFC Industrial Investment } \\
\text { Property \& Leaseho; d fund }\end{array}$ & & Horizon Hospitality & & & \\
\hline 2013 & $\begin{array}{l}\text { - Mapletree GCCT } \\
\text { - SPH REIT } \\
\text { - ouE Hospitality Trust } \\
\text { - Viva Industrial Trust } \\
\text { - Soilbuild Business Space } \\
\text { REIT }\end{array}$ & & $\begin{array}{l}\text { - KLCCP Islamic REIT } \\
\text { - AmAsia Pacific Plus }\end{array}$ & & $\begin{array}{l}\text { - CP Tower Growth Leasehold } \\
\text { Property Fund } \\
\text { - Crystal Retail Growth } \\
\text { Leasehold Property fund } \\
\text { - FN Propery Fund }\end{array}$ & $\begin{array}{l}\text { Regulasi Thai-REIT yang } \\
\text { diperbaharui pada } 2010 \text { baru } \\
\text { benar benar diaplikasikan } \\
\text { secara menyylurutudan PFPO } \\
\text { yang terdaftar disesuaikan } \\
\text { menjadi REIT }\end{array}$ & $\begin{array}{l}\text { - New World Development } \\
\text { REIT } \\
\text {-Ipring REITs } \\
\text { - Hopewell Holdings } \\
\text { - Langham Hospitality } \\
\text { Investments } \\
\text { - New Century Hotel Group / } \\
\text { Kai Yuan Hotels }\end{array}$ & & DIRE Ciptadana & \\
\hline 2014 & $\begin{array}{l}\text { - Keppel DC REIT } \\
\text { - Frasers Hospitality Trust } \\
\text { - OUE Commercial REIT } \\
\text { - IREIT Global }\end{array}$ & & Amanah Harta Tanah REIT & & $\begin{array}{l}\text { - LH Shoopping Centers } \\
\text { Leasehold ERTI } \\
\text { - Pinthong Industrial Park } \\
\text { Property fund } \\
\text { - Hemaraj Industrial Property } \\
\text { \& Leasehold Fund }\end{array}$ & & & & & \\
\hline 2015 & BHG Retail REIT & & Al-Salam REIT & & \begin{tabular}{|l|l|} 
TICON Freehold \& Leasehold \\
REIT
\end{tabular} & & & & & \\
\hline 2016 & \begin{tabular}{|l} 
- Frasers Logistics \& \\
Industrial Trust \\
- Manulife US REIT \\
- EC World REIT
\end{tabular} & & & & \begin{tabular}{|l|} 
Golden Ventures Leasehold \\
REIT \\
- Hemaraj Leasehold REIT \\
- Sripanwa Hospitality REIT
\end{tabular} & & & & & $\begin{array}{l}\text { Regulasi DIRE diperbaharui } \\
\text { oleh OJK dengan beberapa } \\
\text { peringanan regulasi }\end{array}$ \\
\hline 2017 & & & & & \begin{tabular}{|l|}
-CPN Retail Growth Property \\
Fundcc \\
- Gland Office Leasehold REIT \\
- Strategic Hospitality \\
Extendable Freehold \& \\
Leasehod REIT \\
- Dusit Thani Freeehold \& \\
Leasehold REIT \\
- Sub Sri Thai REIT
\end{tabular} & & & & & \\
\hline
\end{tabular}


JURNAL MANAJEMEN BISNIS DAN KEWIRAUSAHAAN/Volume 3/No.2/Maret - 2019 : 48-55

Tabel 2. Perbandingan Regulasi REITs di Singapura, Malaysia, Thailand, Hongkong, dan Indonesia

\begin{tabular}{|c|c|c|c|c|c|}
\hline & Singapura & Malaysia & Thailand & Hongkong & Indonesia \\
\hline Entitas Legal & Trustee & Trustee & Trustee & $\begin{array}{l}\text { Trustee yang wajib terdaftar pada } \\
\text { Bursa Saham Hk }\end{array}$ & $\begin{array}{l}\text { Berbentuk kontrak investasi kolektif } \\
\text { dan tidak wajib terdaftar pada BEI }\end{array}$ \\
\hline Modal Minimal & Min SGD 20 Juta & Min MYR 100 juta atau USD 25 juta & Minimal THB 500 juta & Tidak ada & Tidak ada \\
\hline \begin{tabular}{|l|l} 
Badan \\
Pengelola
\end{tabular} & |Internal/External & External (spesifikasi khusus dari SC) & External & Internal / External & Internal / External \\
\hline \multicolumn{6}{|l|}{ Umum } \\
\hline Kepemilikan & $\begin{array}{l}\text { Minimal } 25 \% \text { dari total unit atau } \\
\text { setidaknya } 500 \text { lembar dimiliki oleh } \\
\text { publik. Boleh dimiliki oleh asing }\end{array}$ & $\begin{array}{l}\text { Tidak ada pembatasan kepemilikan } \\
\text { dan boleh dimiliki warga asing }\end{array}$ & $\begin{array}{l}\text { Pada masa mendaftar minimal terdiri } \\
\text { dari } 250 \text { unit dan perusahaan / } \\
\text { kelompok terafiliasi maksimal } 50 \% \\
\text { dari total. Warga asing boleh memiliki } \\
\text { maksimal } 49 \% \text { dari total unit }\end{array}$ & Bebas & WNA dibatasi \\
\hline Asset & $75 \%$ asset harus berbentuk properti & $\begin{array}{l}\text { Minimal } 60 \% \text { aset berupa properti atau } \\
\text { perusahaan dengan aset tunggal } \\
\text { properti, aset non properti maksimal } \\
25 \% \text {. }\end{array}$ & $\begin{array}{l}\text { Minimal } 75 \% \text { aset berbentuk properti } \\
\text { (yang sudah selesai atau } 80 \% \text { selesai). } \\
\text { Aset properti tidak boleh dijual } \\
\text { setidaknya } 1 \text { tahun setelah diakuisisi }\end{array}$ & \begin{tabular}{|l|} 
Minimal $90 \%$ aset dalam bentuk \\
properti dan maksimal $10 \%$ aset dalam \\
bentuk non properti atau aset yang \\
tidak memberikan pengasilan rutin
\end{tabular} & $\begin{array}{l}50 \% \text { dari Nilai aset bersih harus } \\
\text { berbentuk properti. } 80 \% \text { dari nilai aset } \\
\text { bersih berbentuk properti atau aset } \\
\text { berhubungan dengan properti (saham } \\
\text { properti), aset dalam bentuk lainnya } \\
\text { paling banyak } 20 \% \text {. } \\
\text { Aset tidak boleh dijual dalam masa } 2 \\
\text { tahun sejak diakuisisi }\end{array}$ \\
\hline Pendapatan & $\begin{array}{l}90 \% \text { harus berasal dari pendapatan } \\
\text { sewa }\end{array}$ & $\begin{array}{l}\text { Min 80\% pendapatan M-REITs Syariah } \\
\text { harus dari aktivitas syariah }\end{array}$ & $\begin{array}{l}\text { 75\% pendapatan harus berasal dari } \\
\text { pemasukan sewa properti }\end{array}$ & $\begin{array}{l}90 \% \text { dari penghasilan wajib berasal } \\
\text { dari penghasilan sewa atau dari SPV } \\
\text { yang memiliki aset properti sewa }\end{array}$ & $\begin{array}{l}\text { 90\% pendapatan wajib didistribusikan } \\
\text { kepada pemegang unit }\end{array}$ \\
\hline \begin{tabular}{|l|} 
Batasan \\
Geografis \\
\end{tabular} & tidak ada batasan geografis & tidak ada batasan geografis & tidak ada batasan geografis & tidak ada batasan geografis & Aset harus berlokasi di Indonesia \\
\hline \begin{tabular}{l|} 
Pengembangan \\
Baru
\end{tabular} & $\begin{array}{l}\text { Boleh hanya bila aset akan dikelola } \\
\text { setelah selesai, dan nilainya maksimal } \\
10 \% \text { dari nilai total aset }\end{array}$ & $\begin{array}{l}\text { Tidak boleh melakukan } \\
\text { pengembangan, kecuali pada properti } \\
\text { yang belum selesai dibangun dengan } \\
\text { nilai akuisisi maksimal 10\% dari total } \\
\text { aset }\end{array}$ & \begin{tabular}{|l|} 
tidak boleh melakukan \\
pengembangan. Tetapi boleh \\
mengakuisisi properti yang $80 \%$ \\
selesai dengan nilai maksimal 10\% dari \\
total aset
\end{tabular} & \begin{tabular}{|l} 
Tidak boleh melakukan \\
pengembangan. Namun boleh \\
mengakuisisi properti dalam masa \\
kondstruksi dengan nilai maksimal \\
$25 \%$ dari gross asset
\end{tabular} & $\begin{array}{l}\text { Tidak boleh melakukan } \\
\text { pengembangan }\end{array}$ \\
\hline Gearing Ratio & Maksimal $45 \%$ dari total aset & Maksimal 50\% dari nilai total aset & $\begin{array}{l}\text { Maksimal 35\% dari nilai total aset. Thai- } \\
\text { REITs dengan rating investasi baik dan } \\
\text { memperoleh ijin khusus dari SEC } \\
\text { diperbolehkan meminjam hinga } 60 \% \\
\text { dari NAV }\end{array}$ & Maksimal $45 \%$ dari nilai total aset & $\begin{array}{l}\text { Maksimal 45\% dari nilai aset yang akan } \\
\text { diakuisisi }\end{array}$ \\
\hline \multicolumn{6}{|l|}{ Pajak } \\
\hline $\begin{array}{l}\text { Pajak } \\
\text { Penghasilan }\end{array}$ & $\begin{array}{l}\text { Bebas pajak penghasilan bila } 90 \% \\
\text { dividen didistribusikan }\end{array}$ & $\begin{array}{l}\text { Bebas pajak penghasilan bila } 90 \% \\
\text { dividen didistribusikan }\end{array}$ & $\begin{array}{l}\text { Bebas pajak penghasilan bila } 90 \% \\
\text { dividen didistribusikan }\end{array}$ & $\begin{array}{l}\text { Institusi dikenakan pajak penghasilan } \\
\text { 16,5\%, namun bebas pada tingkat } \\
\text { pemegang unit }\end{array}$ & $\begin{array}{l}10 \% \text { pada tingkat institusi. } 0 \% \text { bagi } \\
\text { pemegang unit }\end{array}$ \\
\hline $\begin{array}{l}\text { Pajak } \\
\text { Peningkatan } \\
\text { Nilai }\end{array}$ & $\begin{array}{l}10 \% \text { dan final kepada investor badan } \\
\text { dan warga negara asing }\end{array}$ & $\begin{array}{l}\text { 10\% (tanpa regulasi khusus dikenakan } \\
15 \% \text { ). Bila dijual dalam masa } 5 \text { tahun } \\
\text { setelah akuisisi dikenakan pajak } 5 \% \\
\text { dari harga jual. } \\
\end{array}$ & Tidak ada & Tidak ada & $10 \%$ \\
\hline Pajak Lainnya & $\begin{array}{l}\text { Stamp duty } 3 \% \text { pada pembelian aset } \\
\text { baru }\end{array}$ & NA & \begin{tabular}{|l|} 
Pajak pendaftaran institusi sebesar $1 \%$ \\
dari pendapatan sewa serta pajak \\
penjualan aset sebesar 0,01\% dari nila \\
transaksi
\end{tabular} & \begin{tabular}{|l} 
Stamp Duty $3,75 \%$ pada penjualan aset \\
eksisting atau akuisisi aset baru.
\end{tabular} & $\begin{array}{l}\text { Stamp Duty } 5 \% \\
\text { PPh 0,5\% bagi pemilik properti yang } \\
\text { menjual aset kepada DIRE }\end{array}$ \\
\hline
\end{tabular}




\section{DAFTAR PUSTAKA}

Block, Ralph L.. (2012). Investing in REITs: Real Estate Investment Trusts. Canada: John Wiley \& Sons, Inc..

CFA Institute. (2011). Asia-Pacific REITs : Building Trust Through Better REIT Governance. Retrieved May 21, 2017, From CFA Institute Website https://www.cfasociety.org/singapore/Documents/CFA\%20Institute\%20Report_AsiaPa cificReits.pdf

Securities and Futures Commisision Tentang Code on Real Estate Investment Trusts. (2010).

EY. (2016). Global Perspectives: 2016 REIT Report. Retrieved April 13,2017, from EY website

http://www.ey.com/Publication/vwLUAssets/global-perspectives-2016-reit-reportey/\$File/ey-global-perspectives-2016-reit-report.pdf

Inland Revenue Authority of Singapore Tentang Income Tax Treatment of Real Estate Investment Trust and Approved Sub-Trusts. (2017).

Keputusan Ketua Badan Pengawas Pasar Modal \& Lembaga Keuangan Tentang Pedoman Bagi Manajer Investasi \& Bank Kustodian yang Melakukan Pengelolaan Dana Investasi Real Estat Berbentuk KIK, No. KEP-425/BL/2007 (2007).

Keputusan Ketua Badan Pengawas Pasar Modal \& Lembaga Keuangan Tentang Pedoman KIK Dana Investasi Real Estate Berbentuk KIK, No. KEP-426/BL/2007 (2007).

Leong, K., Tan, Wenyou and Leong, Elaine. (2014). International REITs : How to Invest Overseas and Build an International Portfolio. Singapore : Marshall Cavendish Business.

Monetary Authority of Singapore Tentang Code On Collective Investment Scheme. (2015).

National Legislative Assembly Functioning as both Houses of Parliament Tentang Securities and Exchange Act. (1992).

National Legislative Assembly Functioning Tentang The Trust for Transactions in Capital Market Act. (2007).

Newell, Graeme and Osmadi, Atasya. (2010). Assessing The Importance Of Factors Influencing The Future Development of REITs In Malaysia. Pacific Rim Property Research Journal, 16 (3), 358-374.

Newell, Graeme and Razali, Muhammad N.. (2009). The Impact Of The Global Financial Crisis On Commercial Property Investment In Asia. Pacific Rim Property Research Journal. 15 (4), 430-452.

Newell, Graeme., Wing, Chau K., Wong, Siu K. and Mckinnell, Keith. (2007). Factors Influencing the Performance of Hongkong Real Estate Companies. Journal of Real Estate Portfolio Management, 13 (1), 75-86

Newell, Graeme., Wu, Yue., Chau, Kwong Wing and Wong, Siu Kei. (2010). The Development and Performance of REITs in Hongkong. Pacific Rim Property Research Journal, 16 (2), 190-205.

Ooi, Joseph T., Newell, Graeme and Sing, Tien Foo. (2006). The Growth of REIT Markets in Asia. Journal of Real Estate Literature, 14 (2), 203-222.

Peraturan OJK Tentang Pedoman Bagi Manajer Investasi Dan Bank Kustodian Yang Melakukan Pengelolaan Dana Investasi Real Estat Berbentuk KIK, No. 19/POJK.04/2016 (2016).

Securities Commission Malaysia Tentang Securities Commission Act. No. 498 (1993).

Securities Commission Malaysia Tentang Securities Commission Act. No. A1539 (2017).

Securities Commission Malaysia. (2005). Securities Commission Malaysia: Regulatory Philosophy. Retrieved April 13, 2017, From SCM Website. https://www.sc.com.my/about-us/sc-regulatory-philosophy/

Strauss, Anselm and Corbin, Juliet. (1998). Basics of Qualitative Research: Techniques and Procedures for Developing Grounded Theory. California: Sage Publication, Inc. 
